\title{
The Japanese Pharmaceutical Industry in Transition: Has Higher Research Orientation Resulted in Higher Market Value?
}

\author{
Jörg Mahlich \\ Austrian Economic Chamber, Wiedner Hauptstr. 63, 1045 Vienna, Austria. \\ E-mail: Joerg.Mahlich@wko.at
}

We analyze here the determinants of market value for 34 listed Japanese pharmaceutical companies between 1987 and 1998. During this period, Japanese pharmaceutical firms increased their investments in basic R\&D in the process of preparing for international market expansion. We provide evidence that international patents significantly contribute to a firm's market value, expressed in Tobin's $q$, while publications in the scientific literature do not contribute to this value. In contrast to earlier studies on the US pharmaceutical industry, such as Gambardella (1992), our findings also suggest that in Japan a firm's publications and patents are not inter-related.

Asian Business \& Management (2007) 6, 75-94. doi:10.1057/palgrave.abm.9200206

Keywords: pharmaceutical industry; Tobin's $q$; R\&D strategy; Japan

\section{Introduction}

The Japanese pharmaceutical industry exemplifies the nation's general drive towards a dominant global standard, a model characterized by high research intensity and high innovative readiness. Pharmaceutical companies that do not follow this lead are destined to forfeit market power. This trend emerged in the late 1980s, up till when Japan's pharmaceutical firms found themselves in an ideal environment for their immediate intents and purposes. Protected from international competition, these firms were able to charge excessive prices for products for which there would be little or no demand on a global scale. The regulatory regime made the pharmaceutical industry by far the most profitable activity in Japan at the time (Odagiri and Yamawaki, 1986). However, times have changed, as the Japanese government has successfully reduced prices for pharmaceuticals and reduced entry barriers for foreign firms. As a result, Japanese companies have witnessed a dramatic decrease in their domestic 
market share. To offset this trend, they have started to redefine their strategies towards a higher degree of internationalization.

However, striving for internationalization is easier said than done, since global pharmaceutical markets are intensely science-based and competition is mainly driven by innovative new drugs offering additional value to patients. The Japanese regulatory regime, however, has favoured incremental innovation and thus local firms had only limited experience with research excellence. Moreover, it was all too often good personal relations with the health authorities that secured fast-track approval of new drugs in Japan, thereby giving Japanese firms a competitive edge over foreign rivals. Success factors in international markets have been totally different. Consequently, it has been difficult for most Japanese pharmaceutical companies to navigate into and within global markets. The path chosen by most Japanese firms has been to increase their R\&D budgets and set up R\&D centres abroad, in order to tap into foreign knowledge bases.

This strategic shift is reflected in the stark increase in scientific publications authored by researchers from Japanese pharmaceutical firms. In other words, Japanese firms have responded to the new challenges with heavy investment in intangible capital. This article examines whether such a strategy has been rewarded by financial markets. In order to do this, we have aimed to estimate the influence intangible capital has on stock market capitalization. Taking patents and scientific publications as indicators of intangible capital stock, our results suggest that only patents drive the market value of a firm; scientific papers authored by company researchers do not. The remainder of this paper provides a brief overview of the Japanese market for pharmaceuticals, before introducing the analytical framework of this empirical exercise. The paper closes with a discussion of the results and a conclusion.

\section{Trends in the Japanese Pharmaceutical Market}

\section{Overview}

Japan's market for pharmaceuticals is the second largest in the world. Although far behind the US, Japan's market size of more than US $\$ 50$ billion of sales in 2003 corresponds to the combined volume of Germany, France, UK and Australia. However, as Table 1 also clearly depicts, the growth rate in Japan is the lowest of all world regions.

Although Japanese firms still dominate their national market, with a share of 64 per cent in 2003, the data clearly show a downward trend. As recently as 1990, Japanese firms controlled 85 per cent of the nation's pharmaceutical market (IMS, 2004). At that time, no foreign firm was among the Top 10 in sales in Japan, and only one made it into the Top 20. With Pfizer, Roche, 
Table 1 TOP pharmaceutical markets 2003

\begin{tabular}{lccc}
\hline World Market & 2003 sales $(\$$ Bn) & $\%$ Global sales & Annual growth rate (\%) \\
\hline North America & 229.5 & 49 & 11 \\
European Union & 115.4 & 25 & 8 \\
Rest of Europe & 14.3 & 3 & 14 \\
Japan & 52.4 & 11 & 3 \\
Asia, Africa, Australia & 37.3 & 8 & 12 \\
Latin America & 17.4 & 4 & 6 \\
Total & $\$ 466.3$ & 100 & 9 \\
\hline
\end{tabular}

Source: IMS Health (2004).

Novartis and Merck, four foreign firms had broken into the Top 10 by 2003 . Also, Pfizer has reached a local market share of six per cent, displacing the local champion, Takeda (5.3 per cent), from the top spot. The market expansion of foreign firms was due to both high growth rates and an increase in M\&A activities. Recently, the biggest deal in the pharmaceutical area was certainly the acquisition of Chugai by its Swiss rival Roche in 2002.

What are the driving forces behind this development? One major issue is certainly easier market access for foreign companies, due to the reduction of market entry barriers. The following section provides a brief review of the liberalization and harmonization measures that have been enacted since the mid-1970s and relaxed market entry conditions for Western companies.

\section{Deregulation}

Japanese legislation began to gradually loosen foreign capital restriction after accession to the OECD in 1964, with foreign minority ownership permitted as of 1967. The first major step in market deregulation, however, took place in 1975, when the Japanese government allowed 100 per cent subsidiaries of foreign pharmaceutical companies to start up business in Japan. Only one year later, Japanese patent law was changed to allow patenting of pharmaceutical product innovations. Until then, Japanese law permitted patent protection only for process innovations. Thus, firms could copy any available molecule without infringing Japanese patent law, as long as they found a new way to manufacture it. As competition in the pharmaceutical industry is driven by new active components and not by innovative process technologies, the patent law effectively hindered the market entry of foreign firms.

The next big step towards harmonization was made in 1997. After 7 years of negotiation within the 'International Conference on Harmonization (ICH)' framework, Japan, the EU and the USA agreed upon the so-called 'Good 
Clinical Practice' guidelines. These guidelines were to harmonize the drug approval process.

Before this landmark agreement, the Japanese Ministry of Health and Welfare (koseisho — in 2001 becoming the Ministry of Health, Labor and Welfare, korosho) only accepted clinical data in cases in which the subjects of drug tests were Japanese. Under these former conditions, approval for a new drug required foreign firms to repeat most of their clinical tests in Japan. Since clinical testing for a new drug requires investment of roughly US\$500 million (DiMasi et al., 2002) and can take up to 7 years (PhRMA, 2004) — not including the time delay dependent on the extent of the testing period - this measure served as an effective market barrier for foreign companies. Upon implementation of the guidelines in 1998, only phase I and parts of phase II tests with Japanese nationals are mandatory (in order to account for smaller body size). These phases involve the testing of around 70 healthy persons with the purpose of assessing a drug's pharmacokinetic properties. If no side effects occur during these stages, firms can skip the expensive phase III clinical trials that would involve several thousand patients. The new guidelines allow foreign firms to make use of clinical phase III data collected elsewhere ('bridging'). Although market observers state that korosho officials still adopt a reserved attitude towards the 'bridging' procedure, this measure undoubtedly has eased market access for foreign drug firms.

The adoption of the relevant ICH guidelines in Japan has also resulted in a significant decrease in the time needed for the review of a drug application. The doubling of review officers has lowered the examination time of new drugs from 3 years in the mid-1990s to an internationally comparable level of about 1 year today (JETRO, 1992; PhRMA, 2004). It is important to note that foreign firms have benefited from this step more than local counterparts. We recall that in the past Japanese firms with close ties to government officials could accelerate approval procedures. The close ties between industry and regulatory bodies are revealed after the retirement of high-ranking civil servants, when many are offered jobs at pharmaceutical firms - a phenomenon known as amakudari, literally 'descent from heaven'.

The most recent deregulation measure was implemented in April 2005, when the accreditation of drug manufacturing was simplified. Previously, a pharmaceutical manufacturer needed to apply for both a manufacturer's permission (shonin) and a manufacturer's license (kyoka). While the shonin certified the safety and efficacy of a drug, the kyoka authorized the manufacturing process. Today, there is only one (marketing) license required. Market observers expect that foreign firms will benefit notably from this measure, as their core competencies have been in R\&D rather than manufacture of drugs. Contrary to Japanese firms, western pharmaceutical 
firms have already outsourced a significant part of their non-core business to external suppliers of speciality materials.

\section{Increased cost consciousness}

Another major trend driving the Japanese pharmaceutical market has been the increased cost consciousness of Japanese health policy. Although Japan's total health bill relative to its GDP is very low in OECD comparisons, drug expenditures are far above average (Figure 1).

The reasons for high Japanese medical consumption lie in the processes of price determination and drug distribution. While drug prices are set by the Central Social Insurance Medical Council (chuikyo), distribution mainly takes place via doctors, rather than pharmacies. Thus, doctors have an incentive to liberally prescribe drugs, especially those with high profit margins, in order to maximize revenue and profits. These margins, called yakka-saeki, arise from the difference between wholesale prices and official list prices, set by chuikyo, for which doctors are reimbursed by health insurance companies. For the year 1987 alone, the absolute value of this margin was estimated to be US\$13 billion (Hisashige, 1997).

In order to reign in the exploding health bill, the Ministry of Health regularly checks pharmaceutical firms' and wholesalers' balance sheets and accounts to determine the difference (margin) between market and list prices, and adjusts the latter to the former. This leads to regular price cuts of sometimes more than 10 per cent every 1-2 years. Price cuts were especially high during the 1980s, when peak values of 18.6 and 16.6 per cent were reached in 1981 and 1984, respectively.

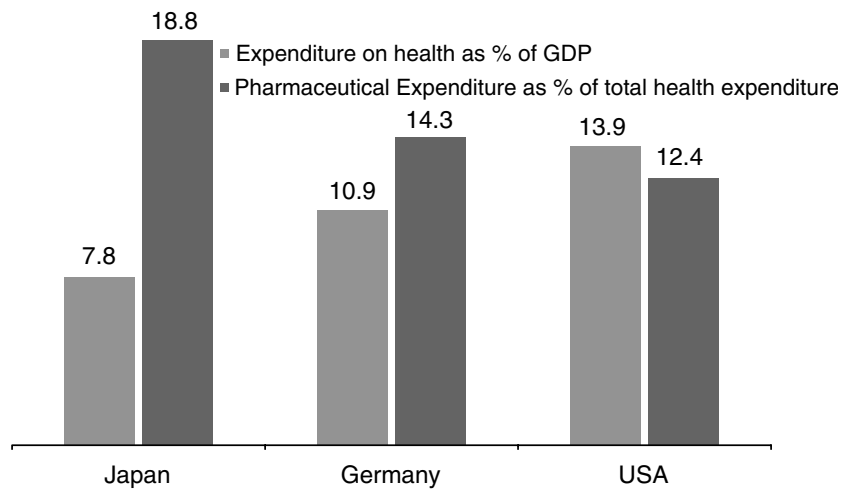

Figure 1 Expenditure on health as percentage of GDP (2001). Source: OECD (2004). 


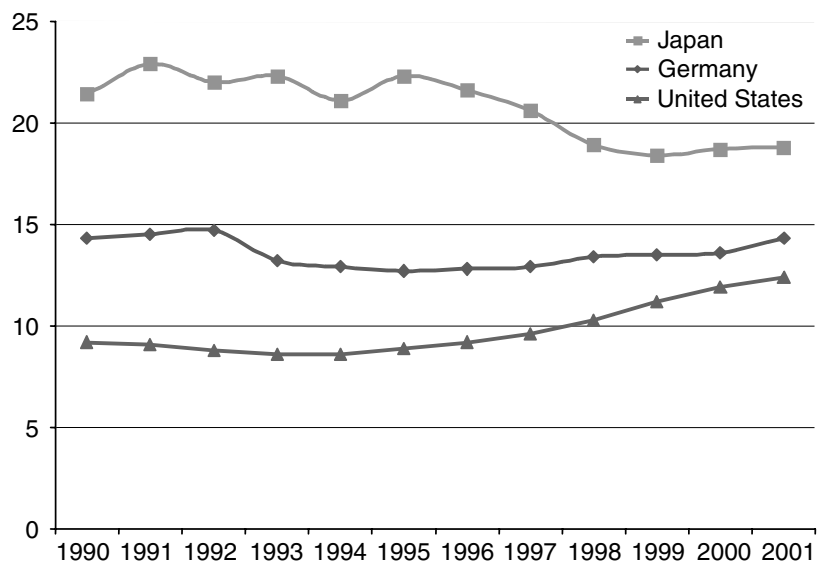

Figure 2 Expenditure on pharmaceuticals as percentage of total health expenditures. Source: OECD (2004).

These price cuts effectively marked the end of the golden age for Japanese pharmaceutical companies, and were associated with measures to promote separation in the prescription and distribution of pharmaceutical products by pharmacies. While only 18 per cent of pharmaceuticals were sold by pharmacies, and the rest in private doctors' practices in 1994, the ratio reached the 50 per cent mark only after 10 years in 2004 .

Both the promotion of pharmacies in drug distribution and the high price cuts successfully lowered the demand for pharmaceuticals. Figure 2 illustrates the downward tendency in pharmaceutical expenditures, despite Japan's rapidly ageing population. Not included in the figure is the period before 1990, which would have underlined the ongoing trend more clearly. For example, the expenditure on pharmaceuticals as a percentage of total health expenditures was, in 1973, as high as 46 per cent.

\section{Research orientation and internationalization}

The increased cost consciousness of Japanese health policy and the reduction of market entry barriers significantly affected the corporate strategies of Japanese pharmaceutical firms. In order to compensate for declining domestic sales, leading Japanese players actively endeavoured to globalize their business activities. Although Japanese firms were virtually absent from the European or US pharmaceuticals market until the 1980s, the picture has now changed to one in which they generate a significant part of their turnover abroad. Table 2 shows how Japanese firms expanded market share in Europe from 0.2 per cent in 1989 to 1.3 per cent in 1999. The gain in market share was even more 
Table 2 Market shares by home region of headquarters (per cent)

\begin{tabular}{lccccccc}
\hline & \multicolumn{3}{c}{1989} & & \multicolumn{3}{c}{1999} \\
\cline { 2 - 3 } & EU 15 & Japan & USA & & EU 15 & Japan & USA \\
\hline North America & 24.7 & 0.1 & 62 & & 24 & 1.9 & 60.2 \\
Europe & 38 & 0.2 & 20.3 & & 45.7 & 1.3 & 26.1 \\
Asia/Africa/Oceania & 10.2 & 51.7 & 11.1 & & 15.4 & 45.8 & 14.4 \\
Latin America & 22.8 & 0.0 & 30.9 & & 26.7 & 0.2 & 29.6 \\
World & 24.7 & 15.7 & 31.2 & & 27.8 & 11.1 & 39.0 \\
\hline
\end{tabular}

Source: IMS, quoted in Gambardella et al., (2000).

impressive in the USA, where it rose from 0.1 to 1.9 per cent during the same period. Nonetheless, a mere 2 per cent of the world's most important pharmaceutical market is not much. Moreover, Table 2 also reveals that the increase in foreign market share was much too small to counterbalance the declining trend on their home turf. In effect, the global market share (including Japan) slumped from almost 16 to just 11 per cent. This means that Japanese firms still have a long way to go if they wish to compete on a global basis.

To achieve a stronger international market presence, Japanese firms established R\&D centres and marketing divisions in major markets. Until recently, however, Japanese firms had only little to offer international customers. As is often the case in protected economic environments, incentives to develop products of outstanding quality were limited and innovation was sluggish, since above-average returns were already being generated with mediocre products. Simply opening a sales office in the USA does not automatically guarantee a boost in drug sales. As a consequence, Japanese firms were forced to undergo cumbersome changes to acquire the competencies needed to succeed in a global environment.

Needless to say, the internationalization process has been far from easy. The pharmaceutical industry is heavily R\&D-driven and economic success lies in the discovery of new products. Since only one in three new market introductions recoups development costs, currently standing at about US\$800 million, firms rely on blockbusters to generate enough profits to compensate for the majority of loss-making drugs (Grabowski et al., 2003). Those blockbuster drugs usually consist of new active compounds that offer fundamentally new treatments for diseases. However, Japanese firms have had only limited experience in such kinds of breakthrough drugs. The main reason for this lies in the principles of the institutional setting described above, in which they primarily developed quasi innovations based on the modification of existing molecules (eg new dosage forms). 
With the establishment of research centres at home and abroad, Japanese firms started to intensify their in-house research capacities to develop the relevant capabilities needed in today's drug industry. An example is Eisai, which led the way in 1987 with the establishment of a basic research lab in Massachusetts, USA. Fujisawa founded a research centre in Edinburgh, UK, only two years later, and Yamanouchi followed in 1990 with a lab in Oxford, UK. A survey by Granstrand (1999) found that the most important motive for establishing research centres abroad was, access to foreign knowledge bases. In the terminology of Kuemmerle (1999), this kind of research centre can be called 'home base augmenting'. This observation is in line with interviews conducted by Kiba and Collinson (1998), who concluded that Japanese R\&D managers rated the quality of US and European basic science higher than that of Japan.

In summary, Japanese firms experienced pressure from deregulation and cost-cutting measures implemented in Japanese health policy during the late 1980s and 1990s. These firms subsequently began building R\&D competences to compete internationally. Focussing firm investments in intangible assets was fundamental to this strategy at the time. In the next section, we explore the economic impact of the strategy shift towards a more intense research orientation. For this purpose, we analyse the relationship between intangible capital on the one hand and market value on the other.

\section{Market value and intangible capital}

Starting with the seminal paper by Griliches (1981), a vast literature has evolved on the relationship between intangible capital and market value.

The pharmaceutical industry provides a good example of the importance of intangible assets, since pharmaceutical firms spend around 10 to 20 per cent of their turnover on R\&D. Like other investments, R\&D investments increase the (intangible) capital stock of a firm. However, balance sheets do not properly account for intangible capital and in effect the amount of intangible capital is underestimated in company reports. For that reason, the firm assets base as reported in a balance sheet can provide only limited insights into the real value of a company. Assuming rational and informed investors, the stock market value of a company gives a much better picture of a company's assets, as it also incorporates the value of the intangible capital stock. In an empirical context, therefore, researchers regress Tobin's $q$ (the ratio of a firm's market value to its book value) on the value of some indicators of intangible capital, like R\&D expenditures or patents.

The pioneering work by Griliches (1981) and Pakes (1985) established a positive relationship between Tobin's $q$ and patent and R\&D stock. Numerous researchers subsequently validated the results (Cockburn and Griliches, 1988; Megna and Klock, 1993; Fleischer, 1999). Using Japanese data on three 
different high-tech industries (drugs, chemicals and electronics), a study undertaken by Haneda and Odagiri (1998) confirmed the results. Moreover, they suggest that the impact of R\&D and patents on a firm's market to book value is up to ten times higher in pharmaceuticals, compared with other industries.

\section{Model}

To examine the relationship between intangible assets and market value, we employed a very basic model, where the market value $V$ of a firm $i$ in period $t$ arises from the value of its physical capital $A$ and intangible capital $K$.

$$
V_{i t}=q\left(A_{i t}+\gamma K_{i t}\right)^{\sigma}
$$

The coefficient $q$ denotes the market valuation coefficient of the firm's assets, ie the multiplier of the market value relative to the replacement costs of total assets. $\gamma$ is the shadow price of the intangible capital stock relative to the physical capital stock. If $\gamma$ is higher than unity, the contribution of intangible assets exceeds that of tangible assets. Estimation results reported by Jaffe (1986) suggest that the coefficient $\gamma$ is around three, that is, the capital market values one dollar of intangible capital three times higher than one dollar of tangible capital.

Taking logarithms in (1) leads to

$$
\log V_{i t}=\log q+\sigma \log A_{i t}+\sigma \log \left(1+\gamma \frac{K_{i t}}{A_{i t}}\right)
$$

If constant returns to scale are assumed, $\sigma$ is unity and the equation becomes

$$
\log \frac{V_{i t}}{A_{i t}}=\log Q_{i t}=\log q+\log \left(1+\gamma \frac{K_{i t}}{A_{i t}}\right) \text {, with } q \text { as Tobin's } q
$$

We approximate the last term by $\gamma\left(K_{i t} / A_{i t}\right)$, which holds for small values of $K / A$ due to $\log (1+X) \approx x$. Therefore, the equation becomes

$$
\log Q_{i t}=\log q+\gamma \frac{K_{i t}}{A_{i t}}
$$

In an empirical context, all the studies mentioned above have in common that they use $R \& D$ and patent data as right-hand variables. It must be considered that $R \& D$ expenditures are an input indicator within the innovation process. Patents, on the other hand, are usually considered an output measure of R\&D investment, with the two variables being highly correlated. This would 
impose a problem from an empirical perspective, since the presence of colinearity would increase the variance of the estimation and thus estimates cannot be held with much confidence. To avoid the above problems, we took patents and publications instead, corresponding to the 'two faces of R\&D' identified by Cohen and Levinthal (1989, 1990). While the number of international patents measures the potential commercial success of $R \& D$ efforts, publications in scientific journals measure competence in the basic research that leads to the development of long-term absorptive capacity. On that note, publications and patents measure basically two different aspects of intangible capital and therefore fit better into the model. Hence, we used both the stock of patents (PATSTO) and the stock of publications (PUBSTO) as proxies for the intangible capital stock $K$. The stock variables were calculated as follows:

$$
\text { PATSTO }_{i t}=\text { PAT }_{i t}+(1-\delta) \text { PATSTO }_{i t-1}
$$

that is, current patent stock equals this period's patents $(P A T)$ plus last year's patent stock, which depreciates at rate $\delta$. Iteration leads to

$$
\begin{aligned}
\text { PATSTO }_{i t}= & P A T_{i t}+(1-\delta) P A T_{i t-1}+(1-\delta)^{2} P A T_{i t-2} \\
& +\ldots+(1-\delta)^{T-1} P A T_{i t-T+1}+(1-\delta)^{T} P A T_{i t-T}
\end{aligned}
$$

Equation (6) can be approximated as

$$
\sim \text { PATSTO }_{i t-T}=\frac{P A T_{i t-T+1}}{\delta+g_{i}}
$$

where $\delta$ is the depreciation rate and $g$ the estimated growth rate of patents and publications. It is calculated for each firm individually. We assume $\delta$ to be 20 per cent, which is between the 13.5 per cent used by Haneda and Odagiri (1998) and the 25 per cent estimated by Pakes and Shankerman (1984).

\section{Data and estimation method}

The sample comprises 34 Japanese pharmaceutical companies during the period 1987-1998. Our sample covers all Japanese corporations that both belong to industry group 283 (drugs) of the 'Standard Industrial Classification (SIC)' System and are listed at the Tokyo stock exchange. The data were collected from various sources. Financial data are from the S\&P global vantage database, whereas pharmaceutical and biotechnological patents are from the European Patent Office. Our patent data include subgroups of the following 'International Patent Classification' (IPC) main groups with reference to biotechnology and pharmaceuticals: A23C11; A23C21; A23C9; A23G3; A23J3; A23K1; A23K1; A23L1; A23L3; A61K31; A61K33; A61K35; 
A61K37; A61K38; A61K39; A61K45; A61K47; A61K49; A61K6; A61K9; C07G11; C12M1; C12N1; C12N1; C12N11; C12N15; C12N5; C12N9; C12P1; C12P13; C12P17; C12P19; C12P21; C12P25; C12P35; C12P41; C12P7; C12Q1. The distribution of patents according to the IPC codes is as follows: A23 (Food or Foodstuffs), 3.5 per cent; A61 (Medical and Veterinary Sciences), 55.7 per cent; C07 (Organic Chemistry), 0.8 per cent; C12 (Biochemistry; Beer, Spirits, Wine, Vinegar, Microbiology, Enzymology, Mutation or Generic Engineering), 39.9 per cent. The patent data were kindly made available to the author by Francesco Lissoni from Bocconi University, Milan.

Our analysis relies on issued patents (EP-B) rather than patent applications, which may or may not result in effective patent protection. The focus on European patents serves as a kind of quality measure, since only major inventions are patented internationally. The numbers of scientific publications are taken from the Medline database. This international database contains over 12 million entries, dating back to the mid-1960s, and covers 4,800 biomedical journals from 71 countries.

The observation period shows a significant increase in the $R \& D$ expenditures ratio as depicted in Figure 3.

Not only the absolute amount of $R \& D$ expenditures increased, but also research intensity, in terms of the $\mathrm{R} \& \mathrm{D} /$ sales ratio (Figure 4).

The increase in R\&D expenditures corresponds to a rise in scientific papers. As Figure 5 reveals, Japanese pharmaceutical companies started to publish extensively in the scientific literature in the late 1980s, until a peak was reached in the mid-1990s. The most active firms regarding publication output were

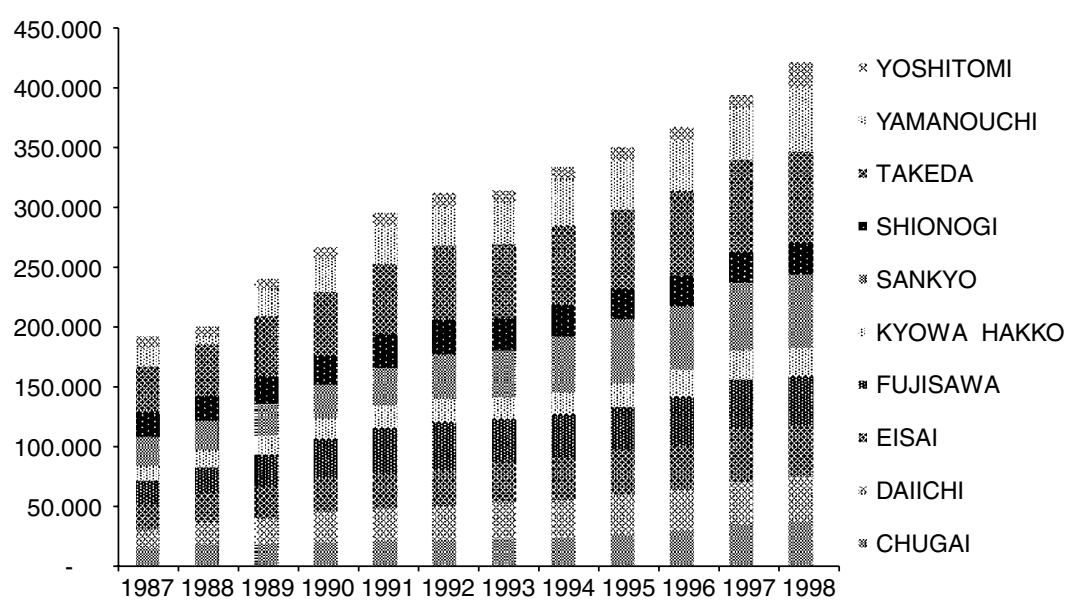

Figure 3 Top 10 firms in terms of R\&D expenditures (Mill. $¥$ ). 


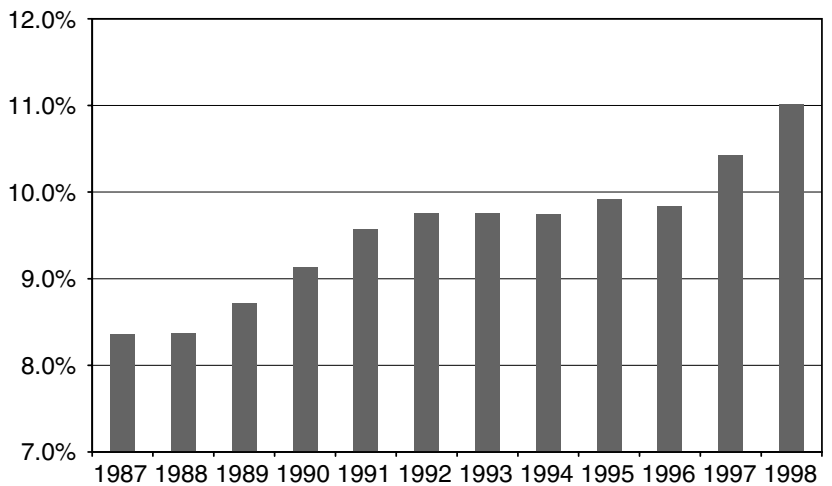

Figure 4 Aggregate R\&D/Sales ratio of 34 leading Japanese pharmaceutical companies.

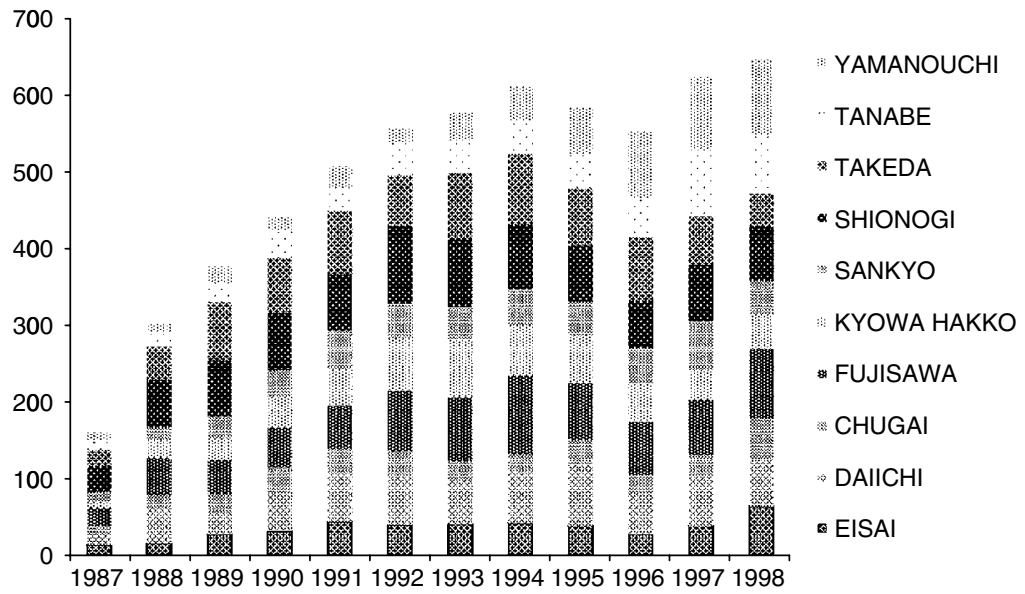

Figure 5 Top 10 firms in terms of scientific publications.

Takeda, with an average of 57.4 papers a year, Fujisawa (56.6) and Daiichi (46.1).

However, the increase in scientific papers was not accompanied by a similar development in patents, as Figure 6 displays; it also nicely reveals the random nature of patent output, even on an aggregate level.

The most significant patenting companies (by number of patents) during the study period (1987-1998) were Kyowa Hakko, with an average of 9.7 patents a year, Yamanouchi (4.1) and Takeda (3.5). In fact, Kyowa Hakko best 


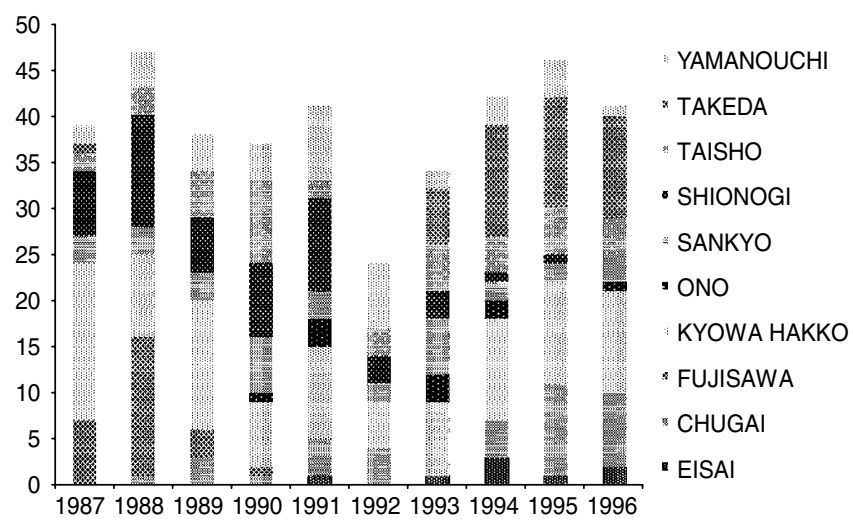

Figure 6 Top 10 firms in terms of EPO patents.

exemplifies the process by which a Japanese firm first intensified R\&D efforts and subsequently expanded into international markets. In 1989, it completed a large R\&D laboratory in Tsukuba and established a company for research and development - Nutri Quest - in the USA. Only 1 year later, two medical representative offices in Düsseldorf (Germany) and New York (USA) were established, which served as drug development bases. In 1992, Kyowa Pharmaceutical commenced operations in the USA, and sales in the UK were initiated a year later in 1993.

The following section presents the results and discusses whether globalization efforts undertaken by Japanese pharmaceutical industry has paid off.

\section{Results and Discussion}

Here, we present the regression results of Equation (4). We employ panel regression techniques with fixed and random effects. Since a Hausman test revealed that the random effects and regressors were correlated, we have discarded the random effects model and report only the results of the fixed effects model. Specification (1) in Table 3 comprises the entire sample for the whole observation period, while specification (2) is limited to the bubble period pre-1990. This particular period deserves special attention, because stock market valuations of firms might have been irrationally exaggerated without reference to real economic indicators. The concept of Tobin's $q$ which acts as our dependent variable, however, assumes a rational assessment of the asset base of a firm. Rational means that a firm's market value can be derived by its future cash-flow stream. Finally, in specification (3), an auto regression term 
Table 3 Estimation results (Tobin's $q$ )

\begin{tabular}{|c|c|c|c|c|}
\hline & $\begin{array}{l}\text { (1) Total sample } \\
\text { (1987-1998) }\end{array}$ & $\begin{array}{c}\text { (2) bubble } \\
\text { period } \\
\text { (1987-1990) }\end{array}$ & $\begin{array}{l}\text { (3) with AR term } \\
\text { total sample } \\
\text { (1987-1998) }\end{array}$ & $\begin{array}{l}\text { (4) with AR } \\
\text { term total sample } \\
\text { (1987-1998) }\end{array}$ \\
\hline Patent stock/assets & $1464.0(1.99)^{* *}$ & $2339.2(2.32)^{* *}$ & $1231.0(1.75)^{*}$ & $1238.5(1.75)^{*}$ \\
\hline Publication stock/assets & $-1456.3(8.05)^{* * *}$ & $-974.0(2.05)^{* *}$ & $-541.5(3.1)^{* * *}$ & $-531.0(3.02)^{* * *}$ \\
\hline Salesgrowth & & & - & $0.02(0.54)$ \\
\hline$R^{2}$ & 0.20 & 0.14 & 0.20 & 0.20 \\
\hline$P>F$ & 0.000 & 0.004 & 0.006 & 0.006 \\
\hline
\end{tabular}

$* * * 99 \%$ significance level, $* * 95 \%$ significance level, $* 90 \%$ significance level, $t$ and $z$ values in parenthesis.

was introduced into the equation in order to account for possible autocorrelation, which typically occurs in panel data. Finally, we experimented with some control variables such as size, as measured by the number of employees, and profitability, as measured by profits on total assets, that may potentially influence Tobin's $q$. Following Hirshey and Weygandt (1985), we also included sales growth in the equation. As the results were not altered much by the control variables, we report only the outcome of the latter specification in column (4).

In all specifications, patent stock positively contributes to a firm's market value, as can be seen from Table 3. This impact was expected and especially strong during the bubble period. Already Mansfield et al. (1981) had concluded that patent protection is key in pharmaceutical innovation, and this assertion still holds true today. Patents serve as the major protective device of new molecules or innovative formulations in the pharmaceutical industry. Our estimated patent stock coefficient is around twice as high as that reported in Haneda and Odagiri (1998), who used local patents issued at the Japanese patent office. As we use patents of the European Patent Office, this result satisfactorily confirms the higher value of international patents.

Regarding the stock of scientific publications, we find a negative relationship that is also highly significant in all specifications. This result is puzzling, since it implies that publications as an indicator of scientific competence seem to reduce a firm's market value. Either publications are not an appropriate indicator of scientific competence or - and this is the more likely explanation - markets assess basic research as costly and attach only limited value to the possible long-term benefits of scientific competence. This might be particularly true in the Japanese case, in which scientific excellence has not been an issue in 
the past. Additionally, even if investors notice the possible benefits of scientific endeavors, they might also be well aware of the risky nature of basic research, because the link between scientific research and a marketable product is very vague. Against this background, publishing activities might be regarded as a waste of time, hindering company researchers from working on their more goal-oriented day-to-day tasks (Allen, 1977). Unless a firm operates close to the scientific frontier, it might economically make more sense to free ride on knowledge created elsewhere.

Moreover, the development of scientific expertise and its potential returns might be impeded by path dependencies. Path dependencies play a very prominent role in the so-called resource-based management literature (eg Conner and Prahalad, 1996). Within this school of thought, path-dependent processes lead to the development of firm-specific capabilities or core competencies that cannot be replicated easily. As Leonard-Barton (1992) rightly noted, core competencies may easily turn into core rigidities in dynamic environments. Firms then find themselves locked in by choices made in the past. In the context of the Japanese pharmaceutical industry, their core competence has been in domestic sales and marketing. These core competencies, however, might turn into core rigidities under changing circumstances. The importance of personal intensive detailing has increased, while requirements on the development side have risen drastically. To diversify competencies is not only a difficult task, but also a very costly and time-consuming one.

The relatively low level of $R^{2}$, which measures the overall fit of the model, is slightly disappointing. Obviously, Tobin's $q$ is driven by many other factors we did not account for. One option to improve the model's goodness of fit would be to include a quality weight of both patents and publications. In the literature, the number of citations in subsequent patents is used for this purpose (Trajtenberg, 1990). Harhoff et al. (1999, 2003) show that the inventor's perception of a patent's economic value correlates with the number of citations. Hall et al. (2000) and Hirshey and Richardson (2001, 2004) find evidence that highly cited patents have a more significant impact on Tobin's $q$ than average patents. Nagaoka (2005) confirms this assertion with Japanese data.

For publications the same argument holds. An introduction of a quality measure, such as the 'journal impact factor' or the number of forward citations, might improve the results. To account for knowledge transfer from universities and public research institutes, one could also imagine analysing coauthorship behaviour. Through collaboration with university researchers, firms can acquire new skills in new areas and gain access to new technology and knowledge (Hicks et al., 1996). Research collaboration in terms of joint publications is therefore believed to have a positive impact on $R \& D$ 
productivity (Zucker and Darby, 1995; Cockburn and Henderson, 2001). Future research certainly should take this issue into consideration.

\section{Plausibility Considerations}

Our results suggest that patents drive a firm's market value, while publications do not. This conclusion only makes sense when patents and publications are not positively related to each other. But a positive relation conjecture is often in the literature. Gambardella (1992), for instance, claimed that scientific publications measure a firm's absorptive capacity, which helps to exploit external knowledge. Using data on US pharmaceutical companies, he found that the number of patents and publications are closely related, which he interprets as evidence for his view. Subsequently, Henderson and Cockburn (1994), Zucker and Darby (1997), Cockburn and Henderson (2001) and Lim (2004) came to similar conclusions.

To check the robustness and plausibility of our result, we investigated in more detail the relationship between patents and publications. Following Gambardella (1992), we assert that the patent discovery process follows a Poisson distribution with parameter $\lambda$ :

$$
P A T_{i t}=\frac{e^{-\lambda_{i t}} \lambda_{i t}^{P A T_{i t}}}{P A T_{i t} !}
$$

Parameter $\lambda$ depends on a vector of explanatory variables $X$. Assuming a $\log$-linear relation between $\lambda$ and the $X\left(\log \lambda_{i t}=\beta X_{i t}\right)$, the expected value of $(8)$ for a given value of $X_{i t}$ is

$$
E\left[P A T_{i t} \mid X_{i t}\right]=\lambda_{i t}=e^{\beta X_{i t}}
$$

Using R\&D expenditures and the number of publications of a firm as explanatory variables, one can write the estimation equation as follows:

$$
\log P A T_{i t}=\alpha+\beta_{1} \log P U B_{i t}+\beta_{2} \log R D_{i t-1}
$$

We estimate this equation with general least squares, Poisson and negative binomial regression methods. The Poisson distribution assumes that the variance of the number of occurrences equals the number of occurrences. Real date often displays over dispersion, meaning that the variance is greater than the expected value. The negative binomial distribution takes account of that by introducing an individual, unobserved effect into the conditional mean. Table 4 exhibits the regression results. 
Table 4 Estimation results (log patents)

\begin{tabular}{lcclc}
\hline & GLS & Poisson & Neg. Bin. & $\begin{array}{c}\text { Poisson (only English } \\
\text { publications) }\end{array}$ \\
\hline Constant & $-4.85(-4.35)^{* * *}$ & $-3.245(3.58)^{* * *}$ & $5.206(0.64)$ & $-3.193(3.50)^{* * *}$ \\
Log PUB & $0.057(0.72)$ & $0.062(0.68)$ & $0.062(0.68)$ & $0.057(0.68)$ \\
Log RD & $0.731(5.60)^{* * *}$ & $0.398(3.53)^{* * *}$ & $0.397(3.53)^{* * *}$ & $0.395(3.56)^{* * * *}$ \\
$P>\chi^{2}$ & 0.000 & 0.000 & 0.000 & 0.000 \\
\hline
\end{tabular}

$* * * 99 \%$ significance level, $* * 95 \%$ significance level, $* 90 \%$ significance level, $t$ values are given in parenthesis.

We see that for our sample of Japanese firms, only R\&D expenditures drive the 'discovery rate' of patents; publications do not. To introduce a kind of quality weight of the publication variable, we limited the analysis to Englishlanguage publications. Even in that case we do not find a relation between publications and patents. This result contradicts Gambardella's (1992) US sample, where the estimated coefficients of the publication variable range between 0.25 and 0.31 , around five times higher than in our (insignificant) Japanese case. However, the results are in line with those of Mahlich (2005). Using firm-level data of European pharmaceutical firms, evidence was found that the number of publications is not correlated with patent applications. In a subsequent paper, Mahlich (2006) argues that the missing link between publications and patents for non-American R\&D labs results from institutional differences in the labor market. American researchers face a greater incentive to publish than their European or Asian counterparts, as publications play a more important role in America, both as an intra- and inter-firm competence signal.

This means that it is not the publication per se that creates value through the development of an absorptive capacity. The causality might be rather the other way round and high-caliber researchers demand the opportunity from their employers to publish in the scientific literature. Applying this reasoning to our Japanese case would mean that companies like Tanabe, which have only a tiny technological base measured in patent grants, need to let their researchers publish just in order to attract good graduates.

\section{Conclusion}

This paper has discussed the strategic response of Japanese pharmaceutical firms to the major challenges of the 1980s and 1990s, namely harmonization of the institutional framework and increased cost consciousness in Japanese health policy. We have argued that Japanese firms reacted with considerable 
investment in the intangible capital required to build up the scientific competence needed for a successful presence in global markets. R\&D investments were associated with international market expansion to compensate for declining domestic sales.

In an empirical exercise, it was shown that such efforts have only partly been rewarded in financial markets. While the patent stock had the expected positive impact on a firm's Tobin's $q$, scientific journal publications were negatively correlated with a firm's market value. This result was explained by possible path dependencies aggravating the diversification of a firm's knowledge base. Although efforts towards the acquisition of long-term absorptive capacity have not fully been rewarded by financial markets, Japanese pharmaceutical firms had no alternative. Thus, the future will certainly bring no reversion of the observed development.

\section{References}

Allen, T. (1977) Managing the Flow of Technology, Cambridge: MIT Press.

Cockburn, I. and Griliches, Z. (1988) 'Industry effects and appropriability measures in the stock market's valuation of R\&D and patents', American Economic Review, Papers and Proceedings 78(2): 419-423.

Cockburn, I.M. and Henderson, R.M. (2001) 'Publicly funded science and the productivity of the pharmaceutical industry', Innovation Policy and the Economy 1: 1-34.

Cohen, W. and Levinthal, D. (1989) 'Innovation and learning: two faces of R\&D', Economic Journal 99: 569-596.

Cohen, W. and Levinthal, D. (1990) 'Absorptive capacity: a new perspective on learning and innovation', Administrative Science Quarterly 35: 128-152.

Conner, K. and Prahalad, C. (1996) 'A resource-based theory of the firm: knowledge versus opportunism', Organization Science 7: 455-501.

DiMasi, J.A., Hansen, R.W. and Grabowski, H.G. (2002) 'The price of innovation: new estimates of drug development costs', Journal of Health Economics 22: 151-185.

Fleischer, M. (1999) 'Innovation, patenting, and performance', Economie Appliquée 52(2): 95-119.

Gambardella, A. (1992) 'Competitive advantages from in-house scientific research: the US pharmaceutical industry', Research Policy 21: 391-407.

Gambardella, A., Orsenigo, L. and Pamolli, F. (2000) Global Competitiveness in Pharmaceuticals, Brussels: European Commission.

Grabowski, H., Vernon, J. and Di Masi, J. (2003) 'Returns on research and development for 1990s new drug introductions', PharmacoEconomics 20(3): 11-29.

Granstrand, O. (1999) 'Internationalization of corporate R\&D: a study of Japanese and Swedish corporations', Research Policy 28: 275-302.

Griliches, Z. (1981) 'Market value, R\&D, and patents', Economic Letters 7: 183-187.

Hall, B., Jaffe, A. and Trajtenberg, M. (2000) 'Market value and patent citations: A first look', NBER working paper series 7741, Washington DC: NBER.

Haneda, S. and Odagiri, H. (1998) 'Appropriation from returns from technological assets and the values of patents and R\&D in Japanese high-tech firms', Economics of Innovation and New Technologies 7: 303-321. 
Harhoff, D., Narin, F., Scherer, F.M. and Vopel, K. (1999) 'Citation frequency and the value of patented innovation', Review of Economics and Statistics 81(3): 511-515.

Harhoff, D., Scherer, F.M. and Vopel, K. (2003) 'Citations, family size, opposition and the value of patent rights', Research Policy 32(8): 1343-1363.

Henderson, R. and Cockburn, I. (1994) 'Measuring competence? Exploring firm effects in pharmaceutical research', Strategic Management Journal 15: 63-84.

Hicks, D.M., Isard, P.A. and Martin, B.R. (1996) 'A morphology of Japanese and European corporate research networks', Research Policy 25: 359-378.

Hirshey, M. and Richardson, V. (2001) 'Valuation effects of patent quality: a comparison for Japanese and US firms', Pacific-Basin Finance Journal 9: 65-82.

Hirshey, M. and Richardson, V. (2004) 'Are scientific indicators of patent quality useful for investors?' Journal of Empirical Finance 11: 91-107.

Hirshey, M. and Weygandt, J. (1985) 'Amortization policy for advertising and research and development expenditures', Journal of Accounting Research 23: 326-335.

Hisashige, A. (1997) 'Healthcare technology assessment and the challenge to pharmaeconomics in Japan', PharmacoEconomics 11(4): 319-333.

IMS Health (2004) IMS World Review, Fairfield: IMS.

Jaffe, A.B. (1986) 'Technological opportunity and spillovers of R\&D: evidence from firm's patents, profits, and market value', American Economic Review 76(5): 984-1001.

JETRO (1992) Your Market in Japan - Pharmaceuticals, 3rd edn, Tokyo: JETRO.

Kiba, T. and Collinson, S. (1998) 'R\&D performance in Japanese companies: a relative evaluation of overseas-based and domestic R\&D', Science and Public Policy 25(4): 227-238.

Kuemmerle, W. (1999) 'Foreign direct investment in industrial research in the pharmaceutical and electronics industries - Result from a survey of multinational firms', Research Policy 28: 179-193.

Leonard-Barton, D. (1992) 'Core capabilities and core rigidities: a paradox in managing new product development', Strategic Management Journal 13: 111-125.

Lim, K. (2004) 'The relationship between research and innovation in the semiconductor and pharmaceutical industries: 1981-1997', Research Policy 33(2): 287-321.

Mahlich, J. (2005) 'Erfolgsfaktoren von forschungsintensiven Firmen am Beispiel der Pharmaindustrie', Die Betriebswirtschaft 75(4): 396-410.

Mahlich, J. (2006) 'Forschungsmanagement in der Pharmaindustrie', Wissenschaftsmanagement, 5: $14-17$.

Mansfield, E., Schwartz, M. and Wagner, S. (1981) 'Imitation costs and patents: an empirical study', Economic Journal 91: 907-918.

Megna, P. and Klock, M. (1993) 'The impact of intangible capital on Tobin's $q$ in the semiconductor industry', American Economic Review 83(2): 265-269.

Nagaoka, S. (2005) Patent quality, cumulative innovation and market value: Evidence from Japanese firm-level panel data, Hitotsubashi University, IIR working paper 05-06, Tokyo: Hitotsubashi University.

Odagiri, H. and Yamawaki, H. (1986) 'A study of company profit rates time series - Japan and the United States', International Journal of Industrial Organization 4: 1-23.

OECD (2004) Health Data, Paris: OECD.

Pakes, A. (1985) 'On patents, R \& D, and the stock market rate of return', Journal of Political Economy 93(2): 390-409.

Pakes, A. and Shankerman, M. (1984) 'The rate of obsolescence of patents, research gestation lags and the private rate of return to research resources', in Z. Griliches (ed.), R\&D, Patents and Productivity, Chicago: University of Chicago Press, pp. 455-503.

PhRMA (Pharmaceutical Research and Manufacturers of America) (2004), 2003 Industry Profile, Washington DC: PhRMA. 
94

Trajtenberg, M. (1990) 'A penny for your quotes: patent citations and the value of innovations', RAND Journal of Economics 21: 172-187.

Zucker, L.G. and Darby, M.R. (1995) Virtuous Cycles of Productivity: Star Bioscientists and the Transformation of Industry, National Bureau of Economic Research (NBER) Working Paper 5342, Cambridge, MA: NBER.

Zucker, L.G. and Darby, M.R. (1997) 'Present at the biological revolution: Transformation of technological identity for a large incumbent pharmaceutical firm', Research Policy 26: 429-446. 